\title{
The Case for Eight Igbo Tones
}

\author{
Iheanacho Ahize
}

\begin{abstract}
Despite research findings to the contrary, many still regard Igbo as a two-tone language, with some recognizing an additional third tone. However, this simplified two-tone system (or two-plus-one system) does not tell the full story of Igbo tones or reflect all the research in Igbo linguistics. Tone testing using a soundboard reveals eight tones (four long and four short ones) which occur in the default pronunciation of common Igbo words and which every Igbo speaker uses frequently. An eight-tone system for individual words better explains the complexity of Igbo tonality and reveals interesting possibilities about the evolution of the Igbo language and its relationship with other tonal languages, such as Chinese.
\end{abstract}

Keywords: Igbo, tones, Chinese

DOI: $10.7176 / \mathrm{JLLL} / 76-04$

Publication date: February $28^{\text {th }} 2021$

\section{Introduction}

Igbo is a member of the Niger-Congo group of languages, the largest phylum in the world (Williamson \& Blench, 2000). It is also part of a functional group, consisting of up to $70 \%$ of the world's languages (Yip, 2002), that are tonal in nature. This means that syllables in Igbo are spoken with a tone (or pitch) in such a way that gives words meaning.

The most commonly used illustration of tone in Igbo language is $a k w a$, which depending on the tones can mean 'cry', 'clothing', 'egg' or 'bed' (Mbah, 2015). Other examples are eze, which can mean 'king' or 'teeth'; afo, which can mean 'stomach' or 'year'; and ozo, which can mean 'again' or a type of chieftaincy title. In Igbo words, tones are as important as spelling. Using a different tone is akin to employing a different vowel or consonant, and the new word so formed will be as distinct to the native Igbo ear as 'bay' is distinct from 'pay' to a speaker of English.

\section{Igbo as a tonal language}

Compared to tones in Chinese, the most widely spoken tonal language, Igbo tones are more versatile, playing a vast array of grammatical roles.

In Chinese, the tones for mŭfàn (rice) do not change in a sentence such as tā zài chĭ mŭfàn (he is eating rice). By contrast, in Igbo $n n i$ (food) as a subject has different tones from nni as an object in, for example, o na eri nni (he is eating food). Likewise, akwa (cry) takes on different tones when someone is actually crying (o na-ebe $a k w a$ ). Similar tone changes occur when words are combined: the tones in isi (head) change when used in onye isi (head person or boss), illustrating the transformation of noun into adjective.

Igbo tones are also more versatile with respect to verbs. In Chinese, the tones for lái (come) or tā (he) do not change in usage such as in tā lái le (he came) or tā lái le ma? (did he come?). In Igbo, on the other hand, o bia (he came) changes its tone-combination in the question o bia? (did he come?). $O$ bia in another tone combination can mean 'if he comes' as in 'if he comes, call me' (o bia, i kpo m). The tone in bia also changes in the imperative form (when asking someone to come, bia!) as it does yet again in the present continuous o na-bia (he is coming).

This is not to say that Igbo is overly complex. Igbo merely uses tones to perform functions that other languages (including tonal ones) may carry out with extra words. However, this feature of Igbo tones, while limited in many languages, is not alien to them. English speakers learn to use tones for questions and exclamations without any effort. Igbo speakers, including language learners, also perform tonal functions without effort. The important thing for Igbo speakers and learners is to be able to pronounce individual words in isolation, using their 'default lexical tones' (Echeruo, 1998). For nouns the default pronunciation is the subject form and for verbs usually the imperative form.

\section{Why we need more tones}

Although researchers have identified several tones over the years (Okoli, 2017), Igbo is still regarded as essentially a two-tone language (Bright-Ajoku \& Okumu, 2020), with a high and low tone corresponding to those in akwa (clothing). While most sources recognize the existence of a third tone, corresponding to the second tone in ego (money), this tone is sometimes represented as a high tone (Echeruo, 1998). In practice, this simplification means that ego (money) and agu (leopard), which sound tonally alike, can have the same tones as $a k a$ (hand) and akwa (cry), which are clearly different in their default pronunciations.

To fit words neatly into a two-tone system, a dictionary entry for aguu (hunger) has the same tones as 
akwukwo (school), whose pitch clearly does not sound similar (Echeruo, 1998). In this example, aguu, which has two syllables, gained a third syllable as did other two-syllable words like isii (six) and asaa (seven). Another dictionary gave aguu the same last tone as agu (leopard), thereby fitting it into a two-plus-one system (Williamson, 2013).

This approach of simplifying the classification of Igbo tones raises an obvious question: how is the reader to know how to pronounce two words that sound different tonally if they are represented in dictionaries with the same tones?

This paper argues that this should not be the case. Igbo does not have two or even three functional tones but at least eight (four short and four long ones) which occur in the default pronunciation of common Igbo words and which every Igbo speaker uses frequently. The proposal for at least eight tones is based on a search of the literature and tone testing, which are detailed below.

\section{The proposed eight}

The first tone is a short high tone that appears in $d i$ (husband) and ji (yam) and twice in akwa (cry), afo (stomach) and ike (strength).

The second tone is a short low tone in $d i$ and $b u$ (which both mean 'is') and in the second syllable of $a \underline{k w a}$ (clothing), obi (heart) and eze (king).

The third and fourth tones are short mid-tones in the first and second syllables of the following words: $a g u$ (leopard), ego (money), nne (mother or a word to address a woman) and nwoke (man). The pair also occurs in the infinitive form of verbs, for example, iri (to eat), ibia (to come) and isi (to cook) and in the last two syllables of okporoko (stock fish). (Okporoko is a useful example of a word containing all four short tones.)

The fifth tone is the long tone in eee (yes), the second syllable of aguu (hunger) and the first syllable of niine (all).

The sixth tone is a long rising tone used in the imperative form of mono-syllabic verbs, for example, when telling someone to come (bia), go (jee) or look (nee). It also appears in the second syllable of ibuo (two), gbafuo (get lost!) or gbasaa (dismiss e.g. a class).

The seventh tone is a sharp long descending tone in the second syllable of asaa (seven) and isii (six). It is also in the first syllable of nwanyi (woman).

The eighth tone is a long high tone that sounds like an elongation of the first. It occurs in the last syllable of gbajie (break), hazie (arrange) and Adichie (the name of a famous writer which Igbo speakers frequently mispronounce) (Adichie, 2021).

\section{The basis for eight tones}

\section{1 literature}

The first two tones (the high and low tones) are the bedrock of the two-tone system. They are well established in the literature and uncontroversial when restricted to the tones in akwa (clothing).

The third tone appears frequently in the literature as the 'step' or 'downstepped' tone (Ikekeonwu, 1991), or simply the mid-tone (Wescott, 1962). This is the tone that occurs in words like ego (money), agu (leopard) and nne (mother or a word to address a woman). In these words, the first syllable is usually assigned the first tone while the last syllable is the third (Odinye \& Udechukwu, 2016). This paper argues that this tone pattern (first plus third) results in an exclamation (nne!) rather than the word spoken in normal relaxed speech (nne). The tone testing described below shows that ego (money) and agu (leopard) in natural speech come with the third and fourth tones rather than the first and third.

The fifth tone appears in the literature as a 'falling tone' (Ward, 1936 and Abraham, 1967). Two researchers, while not indicating that the sixth tone is a distinct one, describe the imperative form of some verbs as having a 'rising melody' (Welmers \& Welmers, 1964). The same researchers identify the sound of the seventh tone in $i$ sii (six) and asaa (seven), describing it as a falling tone that 'must go all the way down to low'.

This paper did not find the fourth and eighth tones in the literature. Even so, the literature to date clearly show that researchers had long understood that there were several tonal sounds in Igbo, and with tone testing it is possible to build on them and obtain a more comprehensive overview of tones for individual Igbo words.

\subsection{Tone testing}

One can show that the eight tones are distinctive by creating a soundboard using an app (See Figure 1). To create the sounds for the first four tones, say 'ma ma ma ma' in the same tones as okporoko (stock fish), recording and saving each syllable as 1 second audio clips. For the fifth tone, say 'ma' with the tone of the last syllable of aguu (hunger), for the sixth say it with the tone of the imperative form of bia (come), for the seventh use the last syllable of asaa (seven) and for the eight the last syllable of hazie (arrange).

The short tones are clearly distinct from the long tones and do not need further differentiation. Although one has to bear in mind that the eighth tone sounds like an elongation of the first. 
To show that each of the short tones are distinct from each other, press the four buttons on the soundboard to produce the tonal sound of okporoko. One finds that pressing the buttons in any order other than 1,2,3,4 does not produce the tonally correct sound. For example, 1,2,3,3 and 1,2,4,4 and 1,2,4,3 all sound different tonally, proving that the third and fourth tones are distinct.

An incidental finding is that pressing 3 and 4 for words such as agu (leopard) and nne (mother or a word to address a woman) produces a similar sound to that of 1 and 3, except that the latter combination sounds like a mild exclamation, while the former reflects normal relaxed speech.

Although there is no single word containing the four long tones, one can test their distinctiveness using different words. For example, one can try to produce the tonal sounds of aguu (hunger) with a combination other than 1,5; the imperative of bia (come) with a tone other than 6; asaa (seven) with a combination other than 2,7, and finally hazie (arrange) with a combination other than 2,8. In all cases, one cannot replace the long tones with any other long tone and still produce a tonally correct sound.

The tone testing therefore reveals that the eight tones are distinct and, furthermore, these tones are found in the default pronunciation of common Igbo words.

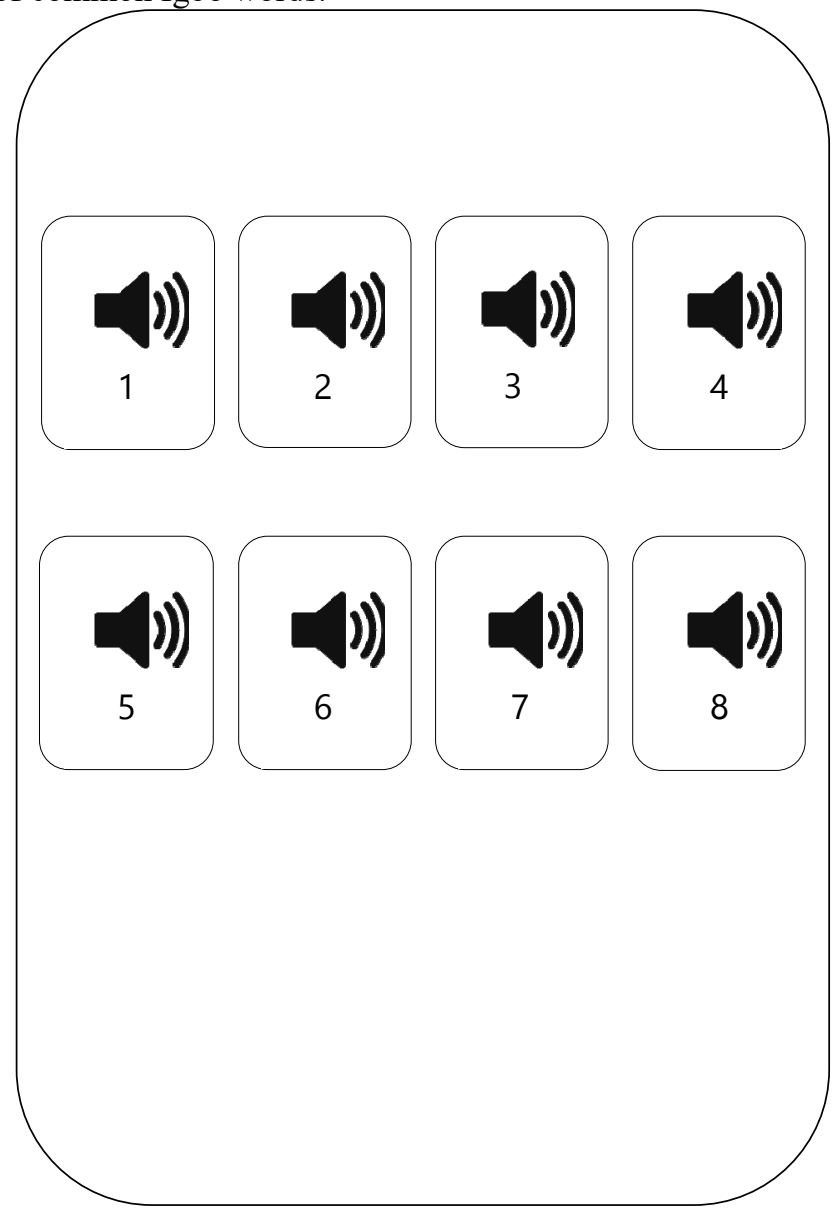

Figure 1. Simple soundboard on an iphone using 'Custom Soundboard Creator' from Anders Bjorkman (version $1.4 .0)$

\section{Concluding remarks}

Igbo speakers will be able to test these tones on their own using a simple app on a phone to create a soundboard. However, it is clear that the simplified two-tone system (or two-plus-one system) does not tell the full story of Igbo tones or reflect all the research in Igbo linguistics.

Given that Igbo uses tones in more ways than Chinese, it is unsurprising that Igbo should have more of them. Indeed, it will be quite obvious to an Igbo-speaking Chinese learner that the four Chinese tones are all present in Igbo. Compare Zhōngguó ('China' in Chinese) with Afam (a name in Igbo); and păobù ('run' in Chinese) with asaa ('seven' in Igbo). A Chinese speaker with instructions to say Afam with the first two Chinese tones and asaa with a (short) third and a fourth Chinese tone will say these Igbo words correctly. (This is further evidence that Igbo should not be considered a two-tone language.)

Some of the Igbo tones in this paper are formed during vowel assimilation or elongation. For example, when ada (eldest daughter) and eze (king) merge to become adaeze, they form a new middle tone which is in 
fact the seventh tone. Another example is obi $m$ (my heart), where the sixth tone is formed. These examples not only illustrate the richness of Igbo tonology but may also throw some light on how the language could have evolved. One may speculate that many words with long tones came from fusions of simpler words and that over time some of the original words fell out of use. One can also speculate that the earliest words in Igbo contained mainly short tones (particularly tones 1 and 2), hence the preponderance of short tones in individual words. Interestingly, the fact that some essential words like eee (yes) and daalu (thank you) do contain long tones could indicate that long tones are part of the DNA of the language.

Moving away from a two-tone system will undoubtedly mean losing some of the benefits of simplicity. Tone marking text with eight signs will be burdensome and confusing since tones of individual words in Igbo change frequently in speech. However, there is a strong case for at least updating dictionaries so that Igbo language learners as well as native speakers can use them as a guide for individual words. The availability of technologies (such as those used by Google Translate) could offer novel ways of developing a new generation of dictionaries for recording the default pronunciation of Igbo words with their appropriate tones.

\section{References}

Abraham, R. (1967). The principles of Ibo (Occasional Publication No.4). Ibadan: Institute of African Studies, University of Ibadan.

Adiche, C. (2021). Interviewed by Ebuka Obi-Uchendu for Bounce Radio Live's Blackbox interviews, 3 January 2021. [Online] Available: https://youtu.be/z_Ec4dtjn1Y?t=23 [Accessed 31 January 2021].

Bright-Ajoku, C. \& Okumu, F. (2020). A Comparative Analysis of Tone in the Igbo and Ukwuani. Journal of Language and Linguistics, Vol. 6. No. 3

Echeruo, M. (1998). Igbo-English Dictionary. A Comprehensive Dictionary of the Igbo Language with an English-Igbo Index. New Haven and London: Yale University Press.

Ikekeonwu, C. (1991). Igbo. Journal of the International Phonetic Association, Vol. 21. No. 2.

Mbah, B. (2015). Toward an Effective Teaching and Learning of the Igbo Tone. Journal of Literature, Languages and Linguistics, Vol. 7.

Odinye, S. \& Udechukwu, G. (2016). Igbo and Chinese Tonal Systems: A comparative Analysis. Ogirisi, Vol. 12.

Okoli, C. (2017). The Tone Marking System of the Igbo Language: A Documentary Overview. Igbo Language Studies, Vol. 2.

Ward, I. (1936). An introduction to the Ibo language. Cambridge: W. Heffer \& Sons Ltd.

Welmers, B. \& Welmers, W. (1964). Igbo. Peace Corps, Washington DC.

Wescott, R. (1962). Two Ibo Songs. Anthropological Linguistics, Vol. 4, No. 3.

Williamson, K. \& Blench, R. (2000) in Heine, B. and Nurse, D. African languages. An introduction. Cambridge: Cambridge University Press.

Williamson, K. (2013). Dictionary of Ònichà Igbo (revised online edition).

Yip, M. (2002). Tone. Cambridge: Cambridge University. 